\title{
Low-pressure endoscopy using the gel immersion method facilitates endoscopic hemostasis of duodenal diverticular bleeding
}

Duodenal diverticular bleeding is an uncommon cause of upper gastrointestinal bleeding, and the optimal treatment remains controversial [1]. Since duodenal diverticula lack a muscle layer, precise endoscopic hemostasis is required to prevent perforation. However, the lumen of the diverticulum easily fills with blood, and the redundant loop in the stomach limits the maneuverability of the endoscope. These factors make precise endoscopic hemostasis difficult.

Gel immersion endoscopy is a new method for securing the visual field using a clear gel. Since the injected viscous gel displaces luminal blood, the bleeding point is easily identified within the gel [2]. In addition, the gel immersion method maintains collapse of the organ with lower intraluminal pressure than with gas insufflation [3], preventing the redundant loop in the stomach.

The patient was a 68-year-old woman with diverticular bleeding in the descending part of the duodenum ( $\triangleright$ Video 1 ). The bleeding point could not be identified using gas insufflation owing to an inadequate visual field and poor maneuverability ( $\triangleright$ Fig.1). Although maneuverability improved after aspirating the gas remaining in the stomach and duodenum, it was difficult to secure the visual field by the water immersion method, because the injected water rapidly mixed with blood. After injecting "Viscoclear" gel (Otsuka Pharmaceutical Factory, Tokushima, Japan) [4], the visual field improved ( $\triangleright$ Fig. 2 ) and the diverticulum with an intraluminal blood clot was identified. Although it was initially difficult to observe the inside of the diverticulum, after attaching a cylindrical hood, it became easier to observe ( $\mathbf{F i g} . \mathbf{3}$ ). The bleeding point at the diverticular septum was identified and endoscopic hemostasis was achieved by clip placement (> Fig.4).

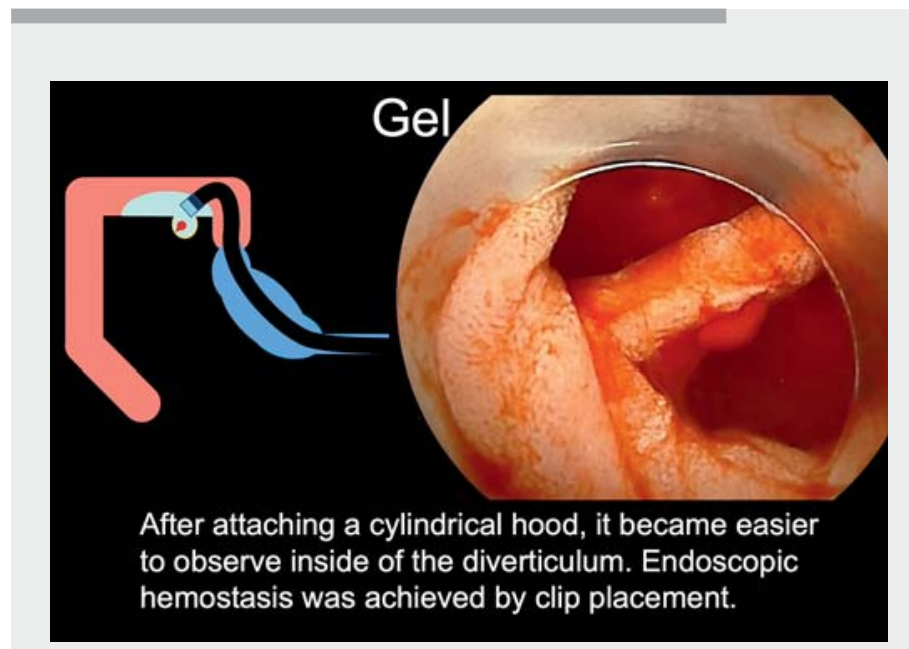

- Fig. 1 The bleeding point could not be identified using gas insufflation owing to an inadequate visual field and poor maneuverability.

Low-pressure endoscopy using the gel immersion method with a cylindrical hood facilitates hemostasis of duodenal diverticular bleeding.

Endoscopy_UCTN_Code_CCL_1AB_2AZ_3AD

\section{Competing interests}

Potential competing interests: Tomonori Yano has patents for the dedicated electrolyte-free gel. No other authors have personal financial relationships with a commercial entity producing healthcare-related products and/or services relevant to this article. 


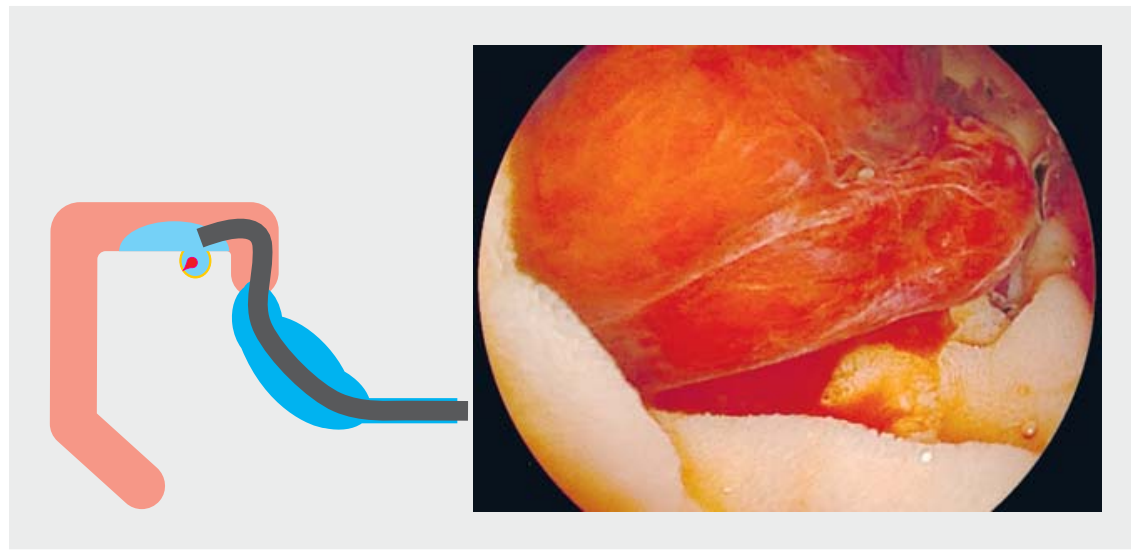

Fig. 2 After injecting "Viscoclear" gel, the visual field improved.
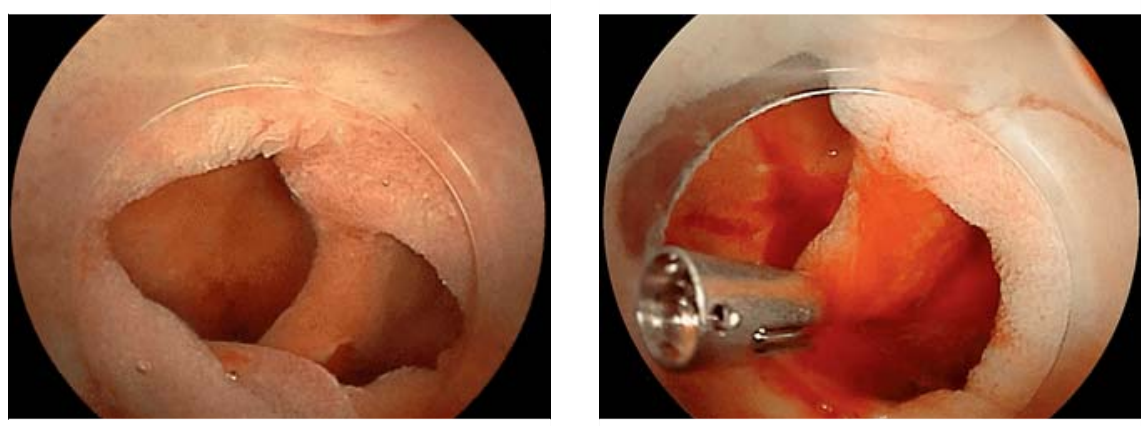

Fig. 3 Although it was initially difficult to observe the inside of the diverticulum, after attaching a cylindrical hood, it became easier to observe.

The authors

Hiroki Hayashi ${ }^{1,2}$, Tomonori Yano ${ }^{1} \bigodot_{\text {, Kunihiko }}$ Oguro $^{1}$, Shiori Yoshimoto ${ }^{1}$, Hiroaki Nomoto ${ }^{1}$, Alan Kawarai Lefor ${ }^{3}{ }^{\oplus}$, Hironori Yamamoto ${ }^{1}{ }^{\circ}$

1 Department of Medicine, Division of Gastroenterology, Jichi Medical University, Tochigi, Japan

2 Department of Community Medicine, Tokushima Prefectural Central Hospital, Tokushima, Japan

3 Department of Surgery, Jichi Medical University, Tochigi, Japan
Fig. 4 The bleeding point at the diverticular septum was identified and endoscopic hemostasis was achieved by clip placement.

\section{Corresponding author}

\section{Tomonori Yano, MD}

Department of Medicine, Division of Gastroenterology, Jichi Medical University, 3311-1 Yakushiji, Shimotsuke, Tochigi, 329-0498, Japan

tomonori@jichi.ac.jp Fax: +81-285-44-8297

[1] Uozumi T, Yane K, Sumiyoshi T. Usefulness of a precisely controllable through-thescope clip for duodenal diverticular bleeding. Dig Endosc 2020; 32: e134-e135

[2] Yano T, Nemoto D, Ono K et al. Gel immersion endoscopy: a novel method to secure the visual field during endoscopy in bleeding patients (with videos). Gastrointest Endosc 2016; 83: 809-811

[3] Yano K, Yano T, Nagayama M et al. Hemostasis of an actively bleeding lesion at the ileocecal valve by low-pressure endoscopy using the gel immersion technique. VideoGIE 2021; 6: 184-186

[4] Yano T, Ohata A, Hiraki Y et al. Development of a gel dedicated to gel immersion endoscopy. Endosc Int Open 2021; 09: E918-E924

Bibliography

Endoscopy 2022; 54: E474-E475

DOI $10.1055 / \mathrm{a}-1625-5596$

ISSN 0013-726X

published online 1.10 .2021

(c) 2021. Thieme. All rights reserved.

Georg Thieme Verlag KG, Rüdigerstraße 14,

70469 Stuttgart, Germany

\section{ENDOSCOPY E-VIDEOS}

https://eref.thieme.de/e-videos

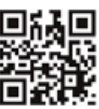

Endoscopy E-Videos is an open access online section, reporting on interesting cases and new techniques in gastroenterological endoscopy. All papers include a high quality video and all contributions are freely accessible online. Processing charges apply (currently EUR 375), discounts and wavers acc. to HINARI are available.

This section has its own submission website at https://mc.manuscriptcentral.com/e-videos 